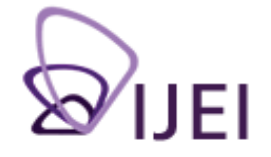

International Journal for Educational Integrity

\title{
Why students plagiarise from the internet: The views and practices in three Norwegian upper secondary classrooms
}

\author{
Håvard Skaar, Postdoctor \\ Oslo and Akershus University College, Norway \\ havard.skaar@hioa.no \\ Hugo Hammer, Associate Professor \\ Oslo and Akershus University College, Norway \\ hugo.hammer@hioa.no
}

Keywords: essay hubs, essay writing, internet, plagiarism

\begin{abstract}
In a two-part mixed methods study, internet-based plagiarism amongst Norwegian upper secondary students was measured and related to performance level and knowledge of source use. Subsequently, interviews were conducted to explore these students' views on internet access and plagiarism during essay writing. The quantitative part of the study showed that $75 \%$ of the 67 students in the study plagiarised from the online sources and that plagiarism accounted for $25 \%$ of the total amount of text. Students with a higher grade in written Norwegian plagiarised less than those with a lower grade. Further, students more familiar with the correct use of sources did not plagiarise as much as students with less awareness. In the qualitative part of the study, individual interviews with 29 of the students indicated that the students wanted to spend as little time and effort as possible on the task and a great majority of the students wanted internet access whether they judged this an obstacle to their learning or not. They also preferred to have free access to internet content regardless of its relevance to the essay, and plagiarism was chosen as a writing strategy regardless of whether or not it was acknowledged to be a moral problem. More proficient writers explained their use of the internet in a more sophisticated way than less proficient writers. With these findings in mind, the different potential consequences of internet access for proficient and less proficient writers are discussed. Finally, some suggestions for further research are put forward.
\end{abstract}

\section{Introduction}

The internet enables students to develop new strategies for advanced writing, but also opens the door to new strategies for plagiarism. Students' inclination to plagiarise has shown an upward trend in recent decades (McCabe, 2001; Schab, 1991), and internet use is often thought to accelerate the plagiarism rate because 'cyberplagiarism' is easier to do and also less morally questioned among students than other kinds of plagiarism (Anderson, 1999; Baruchson-Arbib \& Yaari, 2004; Gajadhar, 1998). The internet also opens up students' access to so-called essay hubs and paper mills. While websites of this category often put some energy into asserting their high moral standards and honest intentions, so-called plagiarism detection services often label them a huge threat creating an urgent need for the services the detection software producers themselves offer. This dynamic has caused some to describe the situation as a 'cat and mouse game' (Furedi, 2000; Young, 2001).

The International Journal for Educational Integrity is available online at:

http://www.ojs.unisa.edu.au/journals/index.php/IJEI/

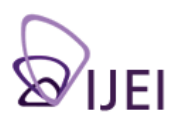


The frequency and amount of plagiarism among students in Norway, e.g. during essay writing with internet access, is uncertain, because cheating and plagiarism are not officially registered in a systematic way at any level in educational institutions in Norway (Karlsen, 2011). Nevertheless, incidences of cheating reported in exams at universities have shown an upward trend for several decades, and this is commonly interpreted as an indication that cheating and plagiarism is a growing problem at the lower levels of the educational system as well (Henneseid, 2011).

The aim of this article is to extend our knowledge of internet-based plagiarism by presenting a study of plagiarism among Norwegian upper secondary students when writing essays with access to the internet. Sixty-seven students in three school classes were free to use internet-based sources while composing an interpretation of a poem or a short story as part of their Norwegian literature studies.

The study consists of two parts in a mixed method design (Creswell, 2012; Creswell \& Plano Clark, 2007). A quantitative analysis of frequency and extent of plagiarism in written assignments handed in by the students in these classes is subsequently combined with the findings from qualitative, semi-structured interviews with students participating in the study.

While the questions in the quantitative part of the study were 'how much?' and 'who?', the question in the qualitative part was 'why?'. Hence, while the quantitative analysis firstly established the frequency and amount of plagiarism among the students in the study, and secondly pointed out variables distinguishing those embarking on plagiarism from those who did not resort to it, the underlying question in the qualitative analysis was why so many of these students opted for plagiarism as a writing strategy.

In the next sections, a summary of results from research on the incidence of plagiarism will be followed by a description of two basic positions on plagiarism in the research literature. Then the methodology of this study will be described, followed by the presentation of the findings in each part of the study. Subsequently, the implications of these findings will be discussed, focusing on the two indicated positions on plagiarism in the existing research literature. On the basis of this evaluation of the findings in the study, we will then address the more difficult question of the potentially more wide-reaching consequences of internet access in regard to students' learning through writing. Finally some suggestions are made for how this study should be followed up in future research.

\section{Prior research}

In this paper plagiarism is used to describe writing practices in concurrence with the following definition:

Plagiarism means submitting work as your own that is someone else's. For example, copying material from a book or other source without acknowledging that the words or ideas are someone else's and not your own is plagiarism. (Davis cited in Cizek, 2003, p. 53)

But although plagiarism is given seemingly clear cut definitions similar to this one in dictionaries and handbooks and on university webpages worldwide, a shared understanding of the term in educational contexts is not easily obtained (Carroll, 2007). While not a term with juridical or financial implications, plagiarism in educational contexts is often understood in the light of copyright law and of implicit or explicit assumptions about language, originality and creativity (Bazerman, 2005; Eisner \& Vicinus, 2008). 
Albeit not in Norway, various aspects of cheating and plagiarism have been researched in other countries for the last 30 to 40 years, especially in the US, UK, Canada and Australia. In surveys charting young people's ethical standards, selfreported plagiarism shows quite high numbers (see e.g. "Who's who among American high school students", 1998). Ma, Wan and Lu (2008, p. 198) refer to a survey of 36,000 high school students by the Josephson Institute of Ethics (2006) in which $33 \%$ reported having "copied an internet document within the past 12 months" and that " $18 \%$ did so two or more times". The same article also makes reference to a survey of 4,500 high school students (Stricherz, 2001) where "About $54 \%$ of respondents reported they had used the internet to plagiarise other people's works" (Ma et al., 2008, p. 199).

Overall, Carrol (2007) emphasises the difficulties of measuring and comparing the rates of plagiarism. She makes reference to Park who points out a great variance in the numbers reported on cheating and plagiarism, but still remarks that plagiarism is "doubtless common and getting more so" (Park cited in Carroll, 2007, p. 23).

Broadly, when plagiarism is discussed in educational settings and educational research, two positions can be outlined: one that sticks to the common definition of "plagiarism-as-stealing" or "plagiarism as deceiving" (Roy, 1999, p. 59) and another that dismisses this ethical stance as less important in an educational context than the pedagogical potentials inherent in the 'remediation' or re-use of the texts of others in so-called 'patchwriting' (Blum, 2009; Howard, 1999; Johnson-Eilola \& Selber, 2007). While holders of the first view tend to complain about a rise in plagiarism among students owing to the proliferation of digital media use, holders of the second typically tend to question whether there is an actual rise in plagiarism (Marsh, 2007, p. 124) and, if so, whether this actually is a problem. The claim of a plagiarism 'epidemic' (Desruisseaux, 1999) is understood as 'moral panic' (Clegg \& Flint, 2006) and the 'policing' (Howard, 2001) of plagiarism is considered unfruitful. Moreover, holders of this position argue that the focus on students' lack of academic integrity (Groom, 2000; Laird, 2001) should be replaced by a focus on the new skills that writing proficiency requires in the digital era. Concurrently, plagiarism detection software should not be used to identify students' wrongdoings but to help students understand and develop the "techniques of textual remediation" which they need to know and master (Marsh, 2007, p. 156). Students' plagiarism is typically explained as a consequence of peer and parent pressure, bad institutional policies and students' lack of time due to the part-time work they must do to finance their studies (see e.g. Blum, 2009).

In contrast, researchers who maintain the 'plagiarism as stealing' approach tend to focus more on 'personal' than 'situational' causes for cheating (Rettinger \& Kramer, 2009). The students themselves, not the educational institution or system, are held responsible for the malpractice, and psychological, pragmatic and also economic models are used to explain students' plagiarism (see e.g. Collins, Judge, \& Rickman, 2007). Education in the use of sources and deterrence by the use of plagiarism detection software are typically suggested as ways to address the problem.

Educational debates are often fueled by ideology, policy or personal beliefs, and in this regard the link between plagiarism and 'morals' or 'moral panic' seems to play out quite forcefully among the holders of both positions sketched out above. More problematically, this ideological positioning quite often seems to predict the empirical claims or assumptions that are put forward. In our view this calls for more factual knowledge of how students actually use internet-based sources in their writing and also about their own understanding of plagiarism as a writing strategy. 


\section{Mixed methods design}

In an explanatory sequential design, collection of quantitative data was followed by collection of qualitative data "to elaborate on the quantitative results" (Creswell, 2012, p. 542).

In the quantitative part of the study we researched the actual incidence of plagiarism among students writing essays with internet access because we considered this important knowledge whether the aim is to deter students from choosing 'cyberplagiarism' as a writing strategy or to help them develop adequate 'techniques of textual remediation' in a new media landscape.

In the qualitative part of the study we interviewed students individually to find out more about their own views on internet access and writing strategies.

The rationale for this two-phase model (Creswell \& Plano Clark, 2007) was a presumption that whether the variables tested in the quantitative analysis were found to be significant or not, the quantitative analysis would still leave open questions as to why students engaged in plagiarism in this particular case. The validity and reliability of the quantitative study were not enhanced by the qualitative follow up. Neither did the quantitative results fortify the findings in the interviews. Thus, mixing the methods was not done for the sake of triangulation but to provide an empirical basis for more in-depth exploration of why plagiarism was chosen as a writing strategy in this case (Collins, Onwuegbuzie, \& Sutton, 2006; Greene, 2006; Tashakkori \& Teddlie, 1998).

\section{Quantitative approach}

\section{Research questions}

Firstly we charted the frequency and extent of plagiarism among the students, and secondly we researched how their level of plagiarism in this case corresponded with gender, grade in written Norwegian and the students' practices and knowledge about the use of sources in writing.

The following research questions were considered:

- What is the frequency and amount of internet-based plagiarism among the students in this study?

- To what extent do gender, grade and knowledge about use of sources predict the students' propensity to plagiarise?

\section{Participants}

The participants were 67 students in three classes in two upper secondary schools in the Oslo area. All three classes were for students following an upper secondary school programme to qualify for higher education. The study was conducted during students' last term in their third and final year of upper secondary school. The participants were 18 to 19 years old, 22 females and 55 males. Most typically they had middle class to upper middle class backgrounds.

The two schools involved had a relatively low performance level compared to other schools in the same geographical area and the students' grades in written Norwegian in the three classes reflected this. 


\section{Procedures}

We designed an essay assignment which the teachers in three upper secondary school classes handed out to their students and later collected and corrected. In the assignment the students were asked to analyse a literary text. In written Norwegian this kind of assignment is common all through upper secondary school and it is also set in final exams nationwide.

The students were given the assignment in advance and were told that they would have a mandatory four-hour writing session to complete the essay in school two to five days later. A four-hour writing session was a default condition when these classes wrote essays for grading, but this time there was a deviation. The normal procedure would be to allow students to bring their laptops to school but to close down the internet connection before handing out the assignment in class. This time the assignments were handed out in advance and the internet was open and free for use while the essays were completed in the classrooms.

The students had two options. They could either analyse a poem written in 1966 by the famous Norwegian poet André Bjerke or they could analyse a short story written by the acclaimed Norwegian writer and filmmaker Sara Johnsen. We selected these literary texts for the assignment after having found out with certainty that no interpretations or analyses of them already existed in textbooks or on the internet. Next, before the students got the assignment we uploaded six completed model answers (three on each of the two literary texts) on so-called essay hubs on the internet. Later, when the students typed the title and name of the author of the poem, three of these model answers would come up on top of the Google search list. For the short story the title was sufficient to make the answers come up on top of the list. We did this so as to know with certainty which sources were available to the students in the format of model answers or interpretations searchable on the internet.

The assignments we had uploaded varied from fairly good to excellent (marks stipulated from $C / B$ to $A+$ ). These essays were uploaded on the essay hubs most frequently used among Norwegian upper secondary students: Daria.no, Propaganda.no and Studienett.no. Norwegian upper secondary students have uploaded assignments and essays from Daria.no and Propaganda.no for more than 15 years. When uploaded, the texts on these websites are freely available for everyone. Studienett.no is a Norwegian branch of a Danish website which has a shorter history in Norway. On this essay hub the students have either to pay by credit card or to upload their own assignments and essays, which also have to pass a quality check, in order to get access to the assignments of others.

In all three classes the assignment was to be handed in at the end of the four-hour writing session in class. Most of the students handed in the assignment at this junction, but some were delayed. A few completed assignments were accepted several weeks after the writing session. All the assignments were then corrected by the class teachers.

\section{Measures}

We measured five variables: the frequency and extent of plagiarism, recent term grade in written Norwegian, gender, education in use of sources, and whether the students provided a reference list.

A software called DiffDoc was used to determine the amount of plagiarised text in the assignments completed by the students. DiffDoc compares two documents and identifies any differences between them. Changes are highlighted in green and additions are highlighted in red, while unchanged text is not highlighted in any way. We determined the percentage of plagiarised text in each essay by comparing the 
student's answer with the assignments we had uploaded on the essay hubs and also with the entries on the authors of the literary texts (André Bjerke and Sara Johnsen) on Wikipedia. McGregor and Streitenberger's (1998) five categories of copying were used to decide what should count as plagiarised text:
A No copying.
B Paraphrasing, doesn't closely resemble original.
C Paraphrasing, can easily recognise original pattern of sentences and paragraphs, but many words have been changed.
D Copying, with phrases rearranged, omitted, some words added. Occasional synonyms used.
E Copied word-for-word for the most part. May involve some omissions, slight rearranging, minimal changing of tenses, minimal use of synonyms.
(McGregor \& Streitenberger, 1998: Appendix)

Text within category $\mathrm{D}$ and $\mathrm{E}$ was coded as plagiarised text. Each student received a score between 0 and 100 depending on the percentage of plagiarised text in the assignment. All the assignments were scored by the first author and one in five assignments were randomly chosen to be scored by the second author. The average deviation between the scores was $5.9 \%$. Using parametric statistics, the distribution of the data should be fairly symmetrically distributed (the measure of skewness should at least be between -1 and 1 ). The transformation of the data from percentage of plagiarism to log (percentage plagiarism +10 ) changed the skewness from 1.15 to 0.26 .

The students' most recent term grade in written Norwegian was used to measure writing proficiency. In Norwegian upper secondary school numerical grades ranging from 1 (poorest) to 6 (best) mirror the same scale as the letter grades (A-F) which are more commonly used abroad. The numerical grade values are used directly in the statistical analysis.

Three weeks before the assignment was handed out the students answered a survey concerning their writing in and out of school. Two questions were about their education in use of sources. The students were asked whether they had learned about use of sources in school and at which level. We used these two questions to measure the students' self-reported education in source use. In the statistical analysis students who answered that they had learned about sources in upper secondary school were given two points, while students who answered that they had only learned about use of sources prior to upper secondary school were given one point. Students who answered that they had not learned about sources at any level were given zero points. The rationale behind this was that we expected that education in use of sources to be less extensive in lower secondary or primary school than in upper secondary school. We also presumed that education in use of sources on levels prior to upper secondary would be less relevant to the task at hand and also more likely to be forgotten by the students.

We also distinguished essays from those that included a list of references at the end from essays with no such list included. While "Education in use of sources" quantified the self-reported education in source use, "Reference list included" measured the students' actual use of sources in this particular case. In the statistical analysis, students who had included a reference list were given one point and students who had not included a reference list were given zero points. 


\section{Qualitative approach}

To find out more about why the students did or did not include plagiarism in their writing strategies we conducted semi-structured interviews with 29 students who were evenly selected from the three classes (Kvale, 1996, 2005). The interviews were done individually, audio taped and were eight to 29 minutes in length. The interviewees comprised a representative distribution of male and female, proficient and less proficient writers. The interviews were conducted a week after the students had handed in the assignment. We were aware of the students' winter term grade in written Norwegian when the interviews were conducted, but at that point we did not know the results of the quantitative part of the study. Thus, we did not in any way relate to the students' actual plagiarism when we interviewed them.

In the interviews the students were basically asked two questions:

- What did you think of doing this assignment?

- What did you think of having internet access while writing the assignment in the classroom?

The students were not asked directly about plagiarism, but most of them brought this topic up themselves when questioned about their internet use during the writing of the assignment. When they did, the topic was pursued by the interviewer. In the analysis, the interviews went through three transformations (Wolcott, 1994). In the first transformation the parts of the interviews where the students in any way related their writing to plagiarism, or gave a possible rationale for plagiarism as a writing strategy, were identified and transcribed. In the second transformation, quotations from the transcripts were grouped under thematic categories related to plagiarism. In the third transformation, the quotations within each thematic category were compared and contrasted in a more fine-grained analysis and specific analytical categories were developed.

The individual interviews were conducted by a researcher with open and pronounced contact with the class teachers. This makes it fair to assume that the students answered the questions as if the questions had been posed by a teacher or any other authoritative figure in the school community. Under condition of anonymity their answers might have been different, but this was not the case and we should therefore factor in the probability that the students answered in a way that allowed them to fend off any accusations of plagiarism in their work with the assignment. Understandably, none of them admitted that they had plagiarised. The students seemed to describe and evaluate their work on the basis of the ideal presumption that in school a motivated and hardworking student would perform a meaningful task and thereby learn something with obvious relevance and importance to their future life, work or education. Students who had chosen writing strategies at odds with this ideal learning situation might, to a greater or lesser extent, have felt a need to make their description of working with the assignment fit with the expectations they ascribed to the teachers and the school community.

\section{Ethical consideration}

All students were asked whether they were willing to participate in the study. When they consented they were told that by giving their consent some of their written assignments would be included in the material to be analysed. Also, they were assured that all collected material would be handled with confidentiality and that no students, classes or schools would be recognisable in publications from the project. 
Before the assignment was handed out the teachers told the students that the assignments would count towards their term grades. However, because internet access in this case created an extraordinary writing situation, the results would only be taken into account if they were likely to improve the finale term grade.

Conversely, if the results of this specific assignment were likely to have a negative impact on the final term grade they would be disregarded. This meant that the naturalistic design of the study was weakened, but at the same time it allowed for a higher degree of transparency and explicit information to the students about which part of their writing would be analysed in our study.

Neither students nor teachers were informed about our uploading of the six completed essays on the essay hubs. Doing this would have made it highly improbable that the students' use of the internet sources would reflect their common practice. When we had analysed the essays the teachers did not receive any information from us about the general frequency and amount of plagiarism nor any indication as to which of the students plagiarised. The study therefore created no extraordinary situation for the teachers or the students. In this respect we followed the same procedures as Nowell and Laufer (1997) did in their study of authentic cheating.

When the interviews were conducted we knew the students' term grade, but not whether he or she had plagiarised or not. For ethical reasons the empirical material in the two parts of the study was not related before the data collection was completed and each part of the data was analysed separately. Only in the final interpretational phase, reflected in the discussion section of this paper, were the results and findings in the two parts of the study actually mixed.

At a later stage, all the students and teachers involved were informed about the procedures described above, in accordance with the guidelines from the Norwegian national committees for research ethics (Forskningsetiske komiteer, n.d.).

\section{Quantitative results}

Seventy five per cent of the students were found to have plagiarised (50 out of 67 ). The average amount of plagiarised text in the essays was $24.7 \%$ (st.d. $28.4 \%$ ). The scope and extent of plagiarism differed in the three classes. In class 1 and 2 nearly all the students plagiarised. The exact numbers were 14 out of 16 students in class 1 and 19 out of 24 students in class 2 . Fewer students plagiarised in class 3 (15 out of 27 students) than in the other two classes. The average amount of plagiarised text in each essay varied concurrently with $35.6 \%$ (st.d. 32 . 9\%) in class $1,30.4 \%$ (st.d. $29.5 \%$ ) in class 2 and the relatively smaller amount of $13.1 \%$ (st.d. $20.1 \%$ ) in class 3.

Figure 1 illustrates the frequency and amount of plagiarism among the students. The $x$-axis represents the number of students and the $y$-axis represents the amount of plagiarised text. A high frequency and amount of plagiarism among the students in the three classes is displayed. A majority of the students plagiarised more than $20 \%$ of their essays and five students plagiarised more than $80 \%$. 

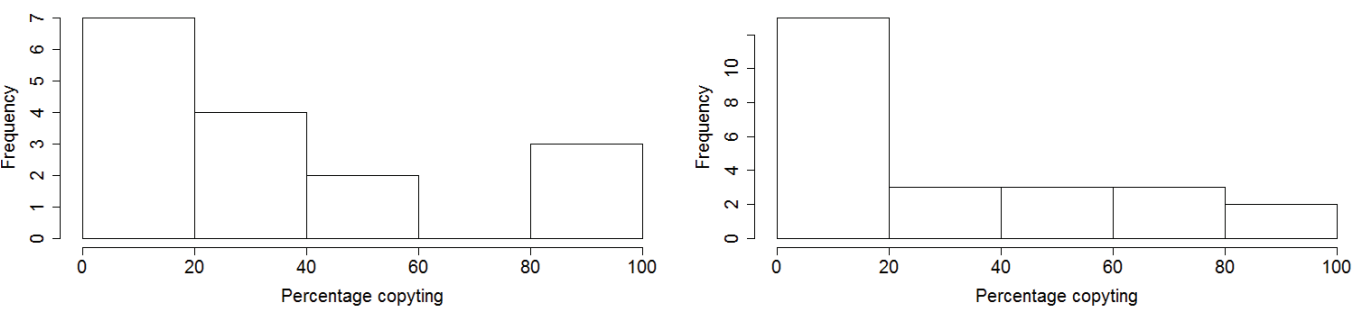

Class 3
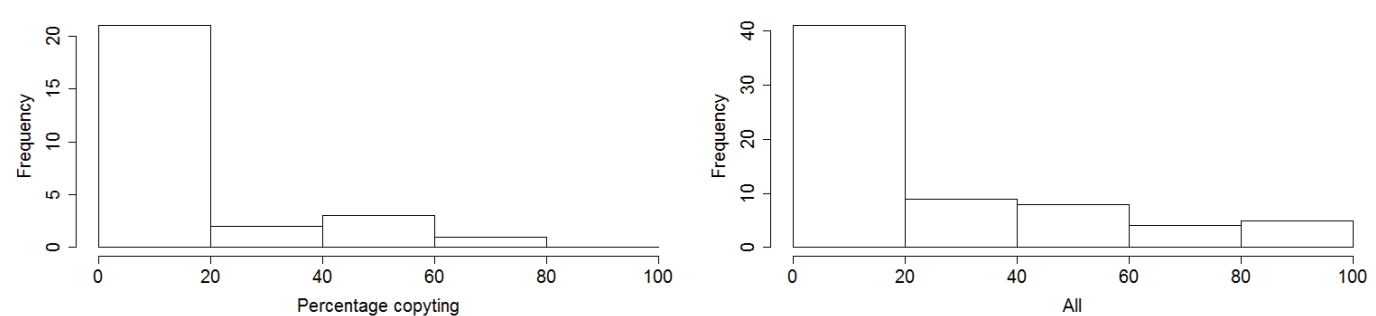

Figure 1: Histograms showing the amount of plagiarism in the students' essays

The histograms in Figure 1 show that the observations are asymmetrically distributed. In Table 1 all relevant means, standard deviations, skewness and correlations are presented.

Table 1:

\begin{tabular}{|l|c|c|c|c|c|}
\hline Variables & 1 & 2 & 3 & 4 & 5 \\
\hline $\begin{array}{l}\text { 1, log (percentage } \\
\text { plagiarism + 10) }\end{array}$ & - & & & & \\
\hline 2, Gender & 0.03 & - & & & \\
\hline 3, Winter term grade & $-0.31^{*}$ & $-0.52^{* * *}$ & - & & \\
\hline 4, Reference list included & $-0.40^{* * *}$ & -0.04 & 0.11 & - & \\
\hline 5, Education in source use & $-0.26^{*}$ & 0.08 & 0.01 & 0.16 & - \\
\hline Means & 3.23 & 0.64 & 3.12 & 0.27 & 0.81 \\
\hline SD & 0.79 & & 0.65 & & 0.39 \\
\hline Skewness & 0.26 & & -0.04 & & -0.82 \\
\hline
\end{tabular}

Means, standard deviations, skewness and Pearson correlations

$\wedge \mathrm{p}<0.10,{ }^{*} \mathrm{p}<0.05, \quad{ }^{* *} \mathrm{p}<0.01, \quad{ }^{* * *} \mathrm{p}<0.001$

Male $=1$, female $=0$

Reference list included: $y e s=1$, no $=0$

The table shows that three variables are significantly correlated to plagiarism in the essays: winter term grade, inclusion of reference list and if the students had been educated in sources. This indicates that students with higher grades plagiarised less than students with lower grades, students who included a reference list at the end of their essays plagiarised less and students who were educated in the use of sources plagiarised less than other students. Grade, inclusion of reference list and source awareness are all negatively correlated to plagiarism and the significances of these correlations are more or less the same, with -0.40 as the highest value. In absolute 
value 0.40 explains about $16 \%$ of the variance. This being the strongest correlation measured we must conclude that none of the variables strongly explains the variance in amount of plagiarism.

After the correlations were established we proceeded with a regression analysis. Since we only have measurements from three classes, it is natural to model school class as a random effect. We therefore analysed the data using a linear mixed-effect regression model with the percentage of plagiarism as dependent variable and school class as a random effect

$$
y_{i f}=\beta^{2} x_{t y}+u_{y}+a_{i p} \quad f=1,2,3
$$

where $y_{i z}$ represents the percentage of copying for student $i$ in class $\beta^{\tau} x_{t i} j$, the fixed effects, the random effect for class $j$ and the error $s_{i j}$ for student $i$ and class $j$. We $u_{j}$ assume that the random effects and the residuals are all independent.

Table 2:

Regression results for percentage of plagiarism

$\wedge p<0.10, \quad{ }^{*} p<0.05, \quad{ }^{* *} p<0.01, \quad{ }^{* * *} p<0.001$

Male $=1$, female $=0$

Reference list included: yes $=1$, no $=0$

\begin{tabular}{|l|c|c|c|}
\hline Variables (Fixed effects) & $\beta$ & Standard error & $p$-value \\
\hline Gender & -0.21 & 0.15 & 0.315 \\
\hline Winter term grade & -0.40 & 0.58 & $0.010^{*}$ \\
\hline Reference list included & -0.57 & 0.21 & $0.007^{* *}$ \\
\hline Education in source use & -0.40 & 0.23 & $0.082^{\wedge}$ \\
\hline
\end{tabular}

Table 2 shows estimates of the fixed effects in the regression model. When controlling for school class and gender, we observe that winter term grade and inclusion of reference list significantly reduced the percentage of copying. Also, with a p-value of 0.082 we have a nearly significant result that students who are trained in use of sources copy less.

\section{Qualitative findings}

The process of working with the interview material gradually led to the development of five analytical categories (1) 'attitudes towards writing essays', (2) 'attitudes towards use of internet-based sources', (3) 'identifying plagiarism', (4) 'strategies to neutralise plagiarism', and (5) 'reflection and writing proficiency'.

\section{Attitudes towards writing essays}

The great majority voiced a negative attitude towards this kind of assignment and at the same time stated that they experienced having internet access while writing essays to be positive. Almost all of the students maintained that they preferred to do written assignments in subjects other than written Norwegian. The great majority typically described analysis of literary text as "boring", "not interesting", "too unspecific" and "difficult". A substantial minority, who were positive about writing assignments in the subject of Norwegian, most typically stated that they were "fond of writing" or that "I like writing essays in Norwegian because it gives me freedom, and I appreciate the freedom of literary analysis". Contrarily, the students who were negative about writing the assignment considered this freedom to be part of the 
problem, either because they found it difficult to decide how the text should be interpreted, or because their own interpretation, as they saw it, had to be close to their teacher's (highly subjective) interpretation to attract a high grade.

In general, the writing strategies described by the students can be explained by a wish to complete the task as fast and effortlessly as possible. The students were required to analyse a poem or a short story, and many of them told us they had chosen the poem because they did not want to spend time reading the short story. Apart from that, 'simpler' and 'faster' were the most frequent explanations for choosing the poem.

\section{Attitudes towards use of internet based sources}

The great majority of the students preferred having internet access during the writing of the assignment and the reason given was primarily that it made the work 'easier'. However, two of the interviewees judged internet access to be to their disadvantage because they assumed that it would make the teacher expect more from their assignment and consequently good grading would be harder to attain.

In the interviews, internet access during writing was most frequently described as a source of "inspiration". The students also described access to the internet as "a helping hand" which made it easier to "get going" and "get ideas" and allowed them to move forward whenever they "were stuck". They could more easily find out whether they were "on the right track" and thereby become more "confident" in their own writing. Reading other people's answers allowed them to "think a bit outside the box" and to "dive a little deeper into the topic" which resulted in a "cooler" assignment. Writing became easier and this made them write more extensively: "...for example, with internet (access) I might write five pages, whereas without I only write two and a half".

The minority of students who were negative about internet access said it actually was of no use in solving the task in hand. They emphasised that internet access made it harder to concentrate on the assignment and resulted in a waste of time:

Internet is negative. One is more easily distracted, (and) some students find similar assignments on the net, then you postpone, you have found an easy solution, (and) you wind up sitting around slacking on Facebook.

One student stated that "Essay writing with internet access is not serious. When you discover that the assignment is done already you lose the inspiration to do it yourself". The lack of concentration could be due to engagement in irrelevant internet use or awareness that peers in the classroom were engaged in this:

Many of the other students were done with their writing, or almost done...so that they could relax and listen to music (and this made it) difficult to concentrate.

On the other hand, some interviewees thought that irrelevant use of the internet could actually help them concentrate better and also prepare them to engage in solving the task:

Surfing the net is no good, but I managed to calm down when I went online.

Although many students claimed that the internet "gives inspiration but makes it difficult to concentrate", it was still the assessment of a great majority that the negative consequences did not outweigh the advantages. The students with a positive 
view on internet access in the writing situation considered irrelevant or disturbing internet use first and foremost to be a problem for other students, not themselves:

Seventy-five per cent of my fellow students in the classroom are on Facebook, YouTube or Spotify every single minute of the day. Evidently, many (students) should not have had internet access (but still) I don't think the internet is an obstacle when it comes to writing... without doubt the internet makes people write more (...) (It's) good for inspiration, getting new ideas, shedding a new light over stuff (...) but sadly I believe the general run of students don't use it (the internet access) as they should. I think most people are sitting around wasting time on the net, doing stuff they shouldn't. For my own part I don't do that.

\section{Identifying plagiarism}

Judged from the comments made by the students in the interviews, the status of model answers uploaded from essay hubs was rather unclear as source material. They seemed often not to be considered sources as defined in their Norwegian lessons but rather to be the work of unknown peers which, if necessary with a bit of rewriting or elaboration, could ease the work the students themselves had to do to complete their assignments.

Although all of the students considered plagiarism to be a problem, some of them were not confident of whether what they had actually written could be classified as plagiarism or not:

If you don't start directly from (do not reproduce exactly) what they have said (or) written, is that cheating then?

Among those not uncertain about what counted as plagiarism, a minority thought the internet should not be accessible during essay writing in school. For example, one student maintained that finding other people's answers on the internet basically "led you to copy, and then write your own paragraph about something else just to have written (something else) as well."

However, the majority of the students emphasised the benefits of internet access which they thought outweighed the problem of plagiarism:

I don't know whether this actually means cheating a little bit. I guess it does, but anyway it did help to get some indication...to get a little hint.

\section{Strategies to neutralise plagiarism}

Moreover, a number of students claimed that the temptation to plagiarise could be fended off by thoughtful writing strategies:

...some people copy the entire answer, but you needs to think for yourself how to use the internet (correctly).

Unconscious plagiarism (cryptomensia) describes the phenomenon of mistaking the ideas of others for one's own (Marsh, Landau, \& Hicks, 1997). One of the students described a strategy which might be labeled "provoked cryptomnesia" to legitimate his use of sources from the internet in his own texts without making any reference or using quotation marks:

First I look around me and I notice the stuff I find reasonable (relevant to the assignment) and then I forget the source and write based on the feelings I got 
(when I was reading the source) and the sense I was making while reading from the source.

Many of the students claimed that strategies to avoid plagiarism regulated their own writing practices but not the practices of others. One student told us that other students could be "a bit too hung up in other people's writing (and then) write something almost similar only expressed a bit differently", but he added that "(personally) I do my own writing first and then I look at what other people have written". On the other hand, more skeptical students claimed that no one really managed to write themselves first and subsequently "flavor with the interpretations of others":

I don't think it's possible to sit around (with internet access) without checking out what other people have written...(I) don't believe you write yourself first, it's impossible (...) you read assignments (of other students) on the net and then you run out of (proper)ideas.

Students with a negative view of internet use, a clear minority, thought that many students would choose to 'copy and paste' because:

....many (students) lack the self discipline needed to be able to write first themselves and then compare with the writings of others. (Actually) first you go into (the internet to look up what other people have written and then you write something yourself).

\section{Reflection and writing proficiency}

Students with above average grades tended to express a more positive attitude to doing the assignment. These students also reflected on their own writing process more in accordance with school-based expectations in regard to use of internet-based sources while completing written assignments. Typically, a student described as a high achiever by her teacher, and consequently with an above average grade in written Norwegian, told us she was "fond of writing" but also thought it was:

... a bit harder to write essays in Norwegian (than written assignments in other subjects) (...) takes more time...hard to get started (therefore) a disposition is important.

She said she had googled the author of the poem and thought it was "helpful to look up other people's assignments" but she also maintained that she had not:

... learned much about using other people's texts in her own writing so then it (the use) easily becomes plagiarism (...) you can get inspiration but it's a bit difficult.

In contrast, a student with poor grades and described by his teacher as having problems with producing any written work at all, told us that when receiving an essay assessment he often thought:

... oh shit...boring ...but if I have internet (access) then I can check in on Facebook, read VG [Norwegian tabloid]...then my motivation might rise ....and make me want to write the essay, yeah?

He told us he had chosen to analyse the short story because he found the short story easier to understand. He did not consider the internet-based access to assignments written by others a problem. This only made him think that he also would be capable 
of doing the task. In addition he found it interesting to view questions and problems "from two different angles".

\section{Discussion}

\section{Quantitative results}

Although most studies indicate the opposite, some researchers still question whether the internet actually leads to more plagiarism (Marsh, 2007; Selwyn, 2008). The results in the quantitative part of this study supported the assumption that it does, as the plagiarism rate was measured to be higher than in any other comparable study.

The unusually high frequency naturally leads to closer investigation of the conditions for students' plagiarism in our study. One obvious reason why the figures for plagiarism were so high in this case was that the students could easily find ready answers on the essay hubs by googling the title and author's name of the texts they were to write about. This will of course not always be the case and if no completed assignments had been accessible on the essay hubs the students would have faced a quite different situation, and the very high frequency and amount of plagiarism must be considered in light of this. The situation the students actually faced was not an unusual situation, however. In the Norwegian context, essay hubs have existed for about 20 years, and thousands of model answers are available at all times for anyone seeking them. There is therefore no reason to suppose that the practice of visiting essay hubs to help with essay papers, as these students did, first occurred in connection with our study. When $75 \%$ of students choose to plagiarise, it suggests the method is familiar and that the writing strategies involving this were well-tried in advance. If this were not the case, it is reasonable to assume that the degree of plagiarism would have been far less.

In our analysis we measured how this plagiarising correlated with proficiency, gender, source recognition and training in source use. We then investigated the relationship between these variables by means of a regression analysis.

Many studies have shown a negative correlation between Grade Point Average (GPA) and plagiarism (Finn \& Frone, 2004; McCabe \& Trevino, 1997; Michaels \& Miethe, 1989; Newstead, Franklyn-Stokes, \& Armstead, 1996; Roig \& DeTommaso, 1995; Whitley, 1998). In this study we did not measure GPA but took the students' most recent term grade in written Norwegian. The grades showed a negative correlation with plagiarism and a unique effect in the regression analysis. This indicates that writing skills and choice of writing strategy with internet access are linked in a way that entails more learning for those who are already good at writing than for those with weaker grades in written Norwegian.

In several studies, boys have shown to be more inclined to cheat and plagiarise than girls (Newstead et al., 1996) although this finding is not consistent (Stevens \& Stevens, 1987). We measured the effect of gender because we assumed that in the context of this study gender would also indicate the student's interest in writing the essay. This is because educational research has generally shown that girls have more interest than boys in reading, writing and interpreting literature (Pajares \& Valiante, 2001; PISA, 2012). Gender showed no significant correlation with plagiarism in our study, although there is a tendency in prior research to indicate that girls are less prone to cheat and plagiarise than boys. It is possible that the low threshold for plagiarism as a writing strategy has evened out the difference between boys and girls in this study. Girls' generally greater interest in reading and writing has had no significant impact either. This may indicate that an interest in the subject must be fairly strong to stem plagiarism from internet-based sources during class essay-writing. 
No one, neither those who plagiarised nor those who did not, quoted correctly from the essays on the essay hub in their written text, but 16 of the students listed the texts from Daria.no as references at the end of their assignment answers. The analysis showed that listing sources in a final reference list had a unique negative effect on plagiarism, while the students' self-reported training in source use was very close to a significant unique effect.

\section{Qualitative results}

In the interviews many students described widespread plagiarism among their peers. Simultaneously, the explanations they gave for this situation were at odds with some of the explanations for plagiarism put forward in prior research. Contrary to claims put forward by other researchers, our study did not support the assumption that plagiarism is due in any noticeable degree to students' lack of knowledge about what plagiarism actually is (Blum, 2009). A few of the interviewees expressed uncertainty, but the great majority knew what plagiarism was, although they lacked the knowledge required for skilful and correct use of the sources they found on the internet. The students felt they were given the time they needed to complete the assignment. Lack of time or procrastination therefore did not explain the plagiarism conducted by the students in this study (in contrast with, for example, Roig \& DeTommaso,1995). Neither did any of the students tell us anything indicating an experience of 'panic' during their work on the assignment, as opposed to what has been found by other researchers (Adler-Kassner, Anson, \& Howard, 2008, p. 243). Nevertheless, the students focused heavily on grades so fear of failure cannot be ruled out as an explanation, as grade pressure is considerable among Norwegian students in their final year of upper secondary school.

The great majority of the students wanted internet access whether they judged this to be an obstacle to their school-based learning or not. The reasons for this were partly an interest in easing the workload and partly an interest in access to media content not relevant to the completion of the task. Some students told us they had completed the assignment as fast as possible so that they could spend the time designated for writing on internet activities they found more entertaining or interesting (e.g. Facebook or Spotify).

\section{Quantitative and qualitative results}

When the plagiarism evident in the students' answers is weighed against what they said about the writing process in the interviews, the possibilities afforded by the internet for ease in the writing process appear more important to the students than the perceived consequences for their own learning outcomes. The students' explanations for choosing to write about the poem instead of the short story reflected a tactical approach to the assignment based on a wish to spend as little time and energy as possible on the writing process.

The interviews indicated that internet access reinforced this approach because the internet made plagiarism easy to do and easy to get away with and at the same time offered the students many tempting alternatives to writing in the time designated for completion of the assignment. When students were asked to describe how their writing process benefited from using the internet, the word 'inspiration' was the most frequent answer. In practice, however, this 'inspiration' led quickly to plagiarism and the respondents' choice of words can be seen as the desire to depict their actual use of online source material as being compatible with the school's requirements and expectations, despite this habit of plagiarising.

In the interviews, most students talked about plagiarism as something they were able to identify, but at the same time the quantitative results indicate that this did not imply that they knew how to use sources correctly. Although some included a reference list none of the students used the source material they found correctly in their writing. 
This may indicate that internet access to sources in this case made it simultaneously easier and more difficult for the students to write the essay. It was easier to write the text making wrong use of sources (i.e. by plagiarising), while it was more difficult to write the text using the source material correctly (since none of the students actually managed to do so, although many reported education in source use). Internet access may therefore result in increased polarisation between those who devote effort to essay writing and those who do not: in other words, an increased divide between proficient and less proficient writers.

This raises the question of whether it is reasonable to suppose that learning through so-called 'patchwriting' (Howard, 1999) can compensate for the loss of learning in those cases when the internet is a resource used primarily with the aim of rendering the writing process as little labour intensive as possible. This study indicates that the weakest students did not progress from inadequate writing to more advanced writing, but from inadequate writing to less or no writing at all.

\section{Literacy implications}

In this study, the internet enabled the students to choose how work-heavy a writing process they wanted. A positive aspect of this might be that writing no longer has the same degree of excluding function as in the past. Those who might formerly have struggled with writing can now produce text with relatively less work and effort. On the other hand, this study also gives reasons to fear that internet access may increase the danger of school-based writing for these students seeming more than ever to be an empty exercise. It can be more difficult to perceive the benefit of developing better writing ability if the text students are expected to write is already accessible to them, regardless of ability.

We were aware of the students' grade level in written Norwegian when the interviews were conducted. When we related the grades to the students' answers, a relationship between skillful writing and skillful reflection on the writing process became apparent. Those who knew how to write also knew how to present their writing as an acceptable practice to the interviewer and thereby also to teachers or other school authorities. Inversely, those who struggled to write also struggled with presenting their writing practices as acceptable in the context of the interview.

This does not suggest a necessary accordance between an uncritical attitude to the use of internet-based sources and the choice of plagiarism as a writing strategy. Only students with above average grades in written Norwegian demonstrated, however, a greater capability to reflect over the learning outcome of their own writing process. Notably, this capability can be acquired and fortified through the writing process itself. Consequently, when the internet makes it easier for anyone to opt out of writing this may pose a more serious threat to less proficient writers because when opting out of writing they are also opting out of the learning emerging from reflection on their own writing process. From this perspective it was the less proficient writers in this study who lost most through having access to the internet during the writing process. By choosing plagiarism they lost out, not only on the possibility of learning how to write, but also on the possibility of developing the capability of reflecting over their writing that the most proficient writers had already acquired. This reflective ability is very important because it applies across all subjects and is therefore a key to academic success (Kleve \& Penne, 2012).

A large majority of the students in this study expressed the view that analysis of literary texts was among the school assignments "they liked least of all". An interest in writing was greater in other subjects, sociology for example. With respect to interest in internet access, the opposite view prevailed. Regardless of the consequences for the learning outcome, the great majority of the students confirmed that they wished access to the internet during the writing process, and although many of them 
described their use of the internet in terms that made it sound compatible with the norms for source use in their Norwegian class, the results show that they tended to plagiarise extensively. The interviews therefore seem to support the theory that assignments more in keeping with students' interests would result in their writing more, while use of the internet, which is in accordance with most students' interests, would tend to result in this wide incidence of plagiarism. The assignment was very unpopular and the internet therefore reinforced the distance between the learning outcomes of the able and less able students.

In other words, the study supports the view that the greater the distance between the assignment text and the students' personal interests, the more restrained one should be in allowing access to the internet during the writing of answers. In all cases, plagiarism is a highly probable consequence of free access to the internet during essay writing and the problems this causes for assessment and leveling must be seriously addressed.

\section{Further research}

This study shows that it is important, while recognising the possibilities offered by the digitisation of writing, not to underestimate the part played by students' interest in minimising effort or economising their investment when answering an essay assignment. A higher number of available writing strategies afford the essay writer more freedom, but this study shows we need to find out more about what happens when the discipline which was formerly an inseparable part of writing activity and which, for that very reason, created a strong aversion to writing among some students, is no longer a prerequisite for essay writing. What are the consequences of the loss of learning resulting from the absence of this discipline? Our study does not answer this question, nor does it give any precise measure of how the internet influenced proficient and less proficient students' learning through writing in this particular case.

It is accordingly important in any future research to clarify whether or not internet access leads inevitably to greater disparity in the effort students with varying degrees of writing skill invest in their essay writing. If it does, access to the internet in writing contexts may prove not to have a leveling effect but, on the contrary, to widen the disparity between students with varying degrees of motivation for writing and of interest and ability.

\section{References}

Adler-Kassner, L., Anson, C. M., \& Howard, R. (2008). Framing plagiarism. In C. Eisner \& M. Vicinus (Eds.), Originality, imitation, and plagiarism: Teaching writing in the digital age. Digital Culture Books.

Anderson, G. L. (1999). Cyberplagiarism. College \& Research Libraries News, 60(5), 371-375.

Baruchson-Arbib, S., \& Yaari, E. (2004). Printed versus internet plagiarism. International Review of Information Ethics, 1(1).

Bazerman, C. (2005). Paying the rent: Languaging particularity and novelty. Plenary address at the University of Michigan Sweetland Writing Center Conference on Originality, Imitation, and Plagiarism, 23-25 September 2005.

Blum, S. D. (2009). My word! Plagiarism and college culture. Ithaca and London: Cornell University Press.

Carroll, J. (2007). A handbook for deterring plagiarism in higher education. Oxford: Oxford Centre for Staff and Learning Development.

Cizek, G. J. (2003). Detecting and preventing classroom cheating: Promoting integrity in assessment. Thousand Oaks, Calif.: Corwin Press. 
Clegg, S., \& Flint, A.( 2006). More heat than light: Plagiarism in its appearing. British Journal of Sociology of Education, 27(3), 373-387.

Collins, A., Judge, G., \& Rickman, N. (2007). On the economics of plagiarism. European Journal of Law and Economics, 24, 93-107.

Collins, K. M. T., Onwuegbuzie, A. J., \& Sutton, I. L. (2006). A model incorporating the rationale and purpose for conducting mixed methods research in special education and beyond. Learning Disabilities: A Contemporary Journal, 4, 67100.

Creswell, J. W. (2012). Educational research: Planning, conducting, and evaluating quantitative and qualitative research (4th ed.). Upper Saddle River, NJ: Pearson Education.

Creswell, J. W., \& Plano Clark, V. L. (2007). Designing and conducting mixed methods research. London: Sage.

Desruisseaux, P. (1999, April 30). Cheating is reaching epidemic proportions worldwide, researchers say. The Chronicle of Higher Education. Lexis-Nexis. U.C. San Diego Central Library. Retrieved March 6, 2003, from http://web-lexisnexis.com.

Eisner, C., \& Vicinus, M. (2008). Originality, imitation, and plagiarism: Teaching writing in the digital age. Ann Arbor, Mich.: University of Michigan Library

Finn, K. V., \& Frone, M. R. (2004). Academic performance and cheating: Moderating role of school identification and self-efficacy. Journal of Educational Research, $97,115-122$.

Forskningsetiske komiteer. Forskningsetiske retningslinjer for samfunnsvitenskap, humaniora, juss og teologi. (Committees for Research Ethics in Social sciences, Humanities, Law and Theology). Retrieved January 20, 2012, from http://www.etikkom.no/

Furedi, F. (2000). Online cat and mouse. Times Higher Education Supplement, 14 July, 16.

Gajadhar, J. (1998). Issue in plagiarism for the new millennium: An assessment odyssey. http://ultibase.rmit.edu.au/Articles/dec98/gajad1.htm.

Greene, J. C. (2006). Toward a methodology of mixed methods social inquiry. Research in the Schools, 13(1), 93-98.

Groom, N. (2000). The fine art of making it by faking it. Times Higher Education Supplement, 7. January, 18-19.

Henneseid, I. M. (2011). Flere studenter blir tatt i juks. VGNett 0704. Retrieved June 5, 2012, from http://www.vg.no/nyheter/innenriks/elevavisen/artikkel.php? artid $=10091853$

Howard, R. M. (2001). Forget about policing plagiarism, just teach. The Chronicle of Higher Education, 12, B12.

Howard, R. M. (1999). Standing in the shadow of giants: Plagiarists, authors, collaborators. Stamford, Conn.: Ablex Publ.

Johnson-Eilola, J., \& Selber, S. A. (2007). Plagiarism, originality, assemblage. Computers and Composition, 24, 375-403.

Josephson Institute of Ethics. (2006). 2006 report card on the ethics of American youth. Retrieved May 9, 2007, from http:// www.josephsoninstitute.org/ reportcard/

Karlsen, H. (2011). Ingen kjenner omfanget av jukset. NRK Nyheter. Retrieved May 4, 2012, from http://www.nrk.no/nyheter/distrikt/nordland/1.7583824

Kleve, B., \& Penne, S. (2012). Cross-curricularity in a literacy perspective: Contrast, confrontation and metalinguistic awareness. International Journal of Educational Research, 55, 48-56.

Kvale, S. (1996). Interviews: An introduction to qualitative research interviewing. Thousand Oaks, CA: Sage.

Kvale, S. (2005). On interpretation in the qualitative research interview. NordiskPedagogik, 25(1), 3-15. 
Laird, E.(2001). We all pay for internet plagiarism. Education Digest, 67(3), 56-60.

Ma, H.J., Wan, G. \& Lu, E.Y. (2008). Digital cheating and plagiarism in schools. Theory into Practice, 47, 197-203.

Marsh, B. (2007). Plagiarism: Alchemy and remedy in higher education. Albany: State University of New York Press.

Marsh, R. L., Landau, J. D., Hicks, J. L. (1997). Contributions of inadequate source monitoring to unconscious plagiarism during idea generation. Journal of Experimental Psychology: Learning, Memory, and Cognition, 23(4), 886-897.

McCabe, D.(2001).Cheating: Why students do it and how we can help them stop. American Educator, 25(4), 38-43.

McCabe, D. L., \& Treviño, L. K. (1997). Individual and contextual influences on academic dishonesty: A multicampus investigation. Research in Higher Education, 38, 379-396.

McGregor, J. H. \& Streitenberger, D. (1998). Do scribes learn? Copying and information use. School Library Media Quarterly Online, 1(1). Retrieved January 3, 2012, from http://www.ala.org/ala/aasl/aaslpubsandjournals/slmrb/ slmrcontents/volume11998slmqo/mcgregor.htm.

Michaels, J. W., \& Miethe, T. D. (1989). Applying theories of deviance to academic cheating. Social Science Quarterly, 70, 870-885.

Newstead, S. E., Franklyn-Stokes, A.,\& Armstead, P. (1996). Individual differences in student cheating. Journal of Educational Psychology, 88, 229-241.

Nowell, C., \& Laufer, D. (1997). Undergraduate student cheating in the field of business and economics. The Journal of Economic Education, 28(winter), 3-12.

Pajares, F. \& Valiante, G.(2001). Gender differences in writing motivation and achievement in middle school students: A function of gender orientation? Contemporary Educational Psychology, 26, 366-381.

PISA (Program for International Student Assessment) Resultatene fra leseprøven. Retrieved June 25, 2012, from http://www.pisa.no/resultater/lesing.html

Rettinger, D.A \& Kramer, Y. (2009). Situational and personal causes of student cheating. Research in Higher Education, 50(3), 293-313.

Roig, M., \& DeTommaso, L. (1995). Are college cheating and plagiarism related to academic procrastination? Psychological Reports, 77, 691-698.

Roy, A. M. (1999). Whose words these are I think I know. In L. Buranen \& A. M. Roy (Eds.), Perspectives on plagiarism and intellectual property in a postmodern world (pp. 55-62). Albany: State University of New York Press.

Schab, F.(1991). Schooling without learning: Thirty years of cheating in high school. Adolescence, 26(104), 839-847.

Selwyn, N. (2008). 'Not necessarily a bad thing...': A study of online plagiarism among undergraduate students. Assessment and Evaluation in Higher Education, 33 (5), 465-479.

Stevens, G. E., \& Stevens, F. W. (1987). Ethical inclinations of tomorrow's managers revisited: How and why students cheat. Journal of Education for Business, 63, 24-29.

Stricherz, M. (2001). Many teachers ignore cheating, survey finds. Education Week, 20(34), 3.

Tashakkori, A., \& Teddlie, C. (1998). Mixed methodology: Combining qualitative and quantitative approaches (Applied Social Research Methods, No.46). Thousand Oaks, CA: Sage.

Whitley, B. E. J. (1998). Factors associated with cheating among college students: A review. Research in Higher Education, 39(3), 235-274.

Who's who among American high school students (1998). Twenty-ninth annual survey of high achievers. Lake Forest.

Wolcott, H. F. (1994). Transforming qualitative data. Descriptions, analysis, and interpretation. Thousand Oaks, London, New Delhi: Sage. 
Young, J.( 2001). The cat-and-mouse game of plagiarism detection. Chronicle of Higher Education, 47(43): A26-A27.

\section{About the authors:}

Håvard Skaar is Postdoctor at the Faculty of Education, Oslo and Akershus University College. He received his $\mathrm{PhD}$ degree from the Faculty of Education, University of Oslo. His most recent research focuses on young peoples' writing and interactions with digital media. He has published numerous peer reviewed articles and chapters and also written popularised presentations of his research, a textbook and reports.

Hugo Hammer received his MS and PhD in statistics from Norwegian University of Science and Technology. He is currently Associate Professor in statistics at the Oslo and Akershus University College. He has published several peer reviewed articles in computational and applied statistics. 